children raises the possibility of respiratory infection, as previously reported in man and birds. The oocyst is small enough to be carried by dust. Much of the inhaled dust (possibly in the form of dried poultry litter) is undoubtedly cleared from the tracheobronchial mucosa by the cilia. It is then swallowed and enters the gastrointestinal tract. Many families in Bangladesh keep their poultry and cattle within their premises. Cryptosporidium was recently detected in $14^{\circ}$ of calves with diarrhoea and $1 \%$ of calves without diarrhoea at a dairy farm in Bangladesh, as well as in $8.5^{\circ}$ of their handlers with diarrhoea. Cryptosporidium was not, however, found in healthy people. $^{5}$

We are now carrying out more extensive studies.

1 Tzipori S. Cryptosporidiosis in animals and humans. Microbiol Rev 1983;47:84-96 Stoll BJ, Glass RI, Huq MI, Khan MU, Holt JE, Banu H. Surveillance of patients attending a diarrhoeal disease hospital in Bangladesh. Br Med f 1982;285:1185-8. highland Costa Rican rural and urban Cryptosporidiosis in children from som Gighland Costa Rican rural and urban areas. Am f Trop.Med Hyg 1984;33:24-9.
Garcia LS, Brewer TG, Bruckner DA, Shimizv RY. Acid-fast staining of Cryptosporidium from human faecal specimens. Clinical Microbiological Newsletter 1982;4(19):60-2.

5 Rahman ASMH, Sanyal SC, Al Mahmud KA, Sobhan A, Hossain KS, Anderson BC. Cryptosporidiosis in calves and their handlers in Bangladesh. Lancet
$1984 ; \mathrm{ii}: 221$.

(Accepted 24 September 1984)

International Centre for Diarrhoeal Disease Research, GPO Box 128, Dacca 2, Bangladesh

NIGAR S SHAHID, MB, MSC, assistant scientist

A S M H RAHMAN, DVM, MSC, veterinary officer

B C ANDERSON, DVM, PHD, consultant

L J MATA, DSC, consultant

S C SANYAL, MD, PHD, consultant

Correspondence to: Dr Nigar S Shahid.

\section{Relation between dentition and dyspeptic disorders}

There is a dearth of information relating the state of the teeth to dyspepsia. This study examined a theory that a disproportionately high number of patients with gastric ulcer and gastric cancer were edentulous.

\section{Patients, methods, and results}

From a consecutive series of 400 patients undergoing endoscopy 291 patients fell into the four categories of normal endoscopic findings, gastric ulcer, duodenal ulcer, and gastric cancer; their ages and dentition were recorded. By a subsequent questionnaire to 100 of the patients selected at random we determined the chronological relation between total loss of natural teeth and onset of dyspepsia and whether the patients wore dentures at meal times. To investigate the association of each category with dentition, allowing for age, we divided the patients into age groups of five years. Within each group we constructed a contingency table of dyspepsia against dentition. From each of these tables the expected number of patients with dentures within each category of dyspepsia was calculated under the nul hypothesis that dentition and disease were unrelated. Finally, we summed the expected numbers of patients with dentures within the categories of dyspepsia over all ages and compared them with the observed numbers. We assessed the significance of the association with a $\chi^{2}$ test based on the expected and observed numbers in this pooled contingency table. ${ }^{1}$

The table shows the use of dentures by the patients in the four categories and their mean ages: lack of natural teeth was commonest among the patients with gastric ulcer and gastric cancer. These patients were also older. When the observed numbers of patients with and without dentures were compared with the expected numbers there was no significant

Cross tabulation of endoscopic findings with dentition in patients with dyspepsia, after allowing for age

\begin{tabular}{|c|c|c|c|c|}
\hline & $\begin{array}{l}\text { Normal } \\
\text { findings } \\
(\mathrm{n}=85)\end{array}$ & $\begin{array}{c}\text { Duodenal } \\
\text { ulcer } \\
(n=133)\end{array}$ & $\begin{array}{c}\text { Gastric } \\
\text { ulcer } \\
(n=59)\end{array}$ & $\begin{array}{c}\text { Gastric } \\
\text { cancer } \\
(n=14)\end{array}$ \\
\hline 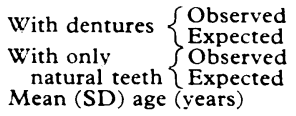 & $\begin{array}{l}38\left(45{ }^{\circ}\right) \\
43 \cdot 9 \\
47 \cdot 1 \\
41 \cdot 1 \\
52 \cdot 0(17 \cdot 7)\end{array}$ & $\begin{array}{l}79(59 \cdot 10) \\
76 \cdot 7 \\
54 \\
56 \cdot 3 \\
54 \cdot 2(15 \cdot 1)\end{array}$ & $\begin{array}{l}46(78 \%) \\
41 \cdot 9 \\
13 \\
17 \cdot 1 \\
62 \cdot 2(12 \cdot 8)\end{array}$ & $\begin{array}{l}12(86 \%) \\
12 \cdot 4 \\
2 \\
1 \cdot 6 \\
75 \cdot 2(12 \cdot 0)\end{array}$ \\
\hline
\end{tabular}

association between dentition and category of dyspepsia after allowing for age $\left(\chi^{2}=3.3, \mathrm{df}=3,0.3<\mathrm{p}<0.4\right)$

The chronological relation between onset of dyspepsia and total loss of natural teeth could be clearly defined in 89 patients. Sixty three had lost their teeth before the onset of dyspepsia. This was true for all categories. No difference was found in the duration of dyspepsia before endoscopy between patients with only natural teeth and those with dentures. Only six patients admitted to removing their dentures before a meal.

\section{Comment}

There have been few reports in the past 50 years of a relation between diseases of the upper alimentary tract and dentition. In 1929 Hurst and Stewart attributed peptic ulcer of the stomach and duodenum to carious teeth and apical abscesses, based on an increased prevalence of caries in patients with ulcers compared with normal controls": "sound" teeth were present in $19 \%$ of patients with ulcers compared with $48 \%$ of controls. These observations have not been confirmed. Draper et al, from anthropometric measurements, identified a jaw shape and disposition of teeth that they regarded as being of "ulcer type,"3 but they did not provide any data to substantiate this. Differences in the prevalence of peptic ulcer in various regions of India have been attributed to differences in the demand for mastication by the type of food eaten and in the quantity and content of saliva, but the dental state was not reported. ${ }^{4}$ In a survey of dental health in Scotland $45 \%$ of subjects aged $35-54$ and $83 \%$ of those aged 55 plus had lost all their teeth. ${ }^{5}$ The ratio of full to partial dentures in our patients was $4: 1$, and $67 \%$ had no natural teeth. The theory that most patients with gastric ulcer and gastric cancer are edentulous was confirmed, but this would be expected from their age.

In conclusion, loss of teeth generally precedes dyspepsia and was observed in all clinical categories including patients with normal endoscopic findings. Though lack of teeth may have a role in some cases of dyspepsia, it can be only a minimal one.

We thank Dr M A Maksoud for his help in recording some of the data.

1 Armitage P. Statistical methods in medical research. Oxford: Blackwell, 1971:373-5. 1 Armitage P. Statistical methods in medical research. Oxford: Blackwell, 1971:373-5. Press, 1929 .

Draper G, Dupertuis CW, Caughey JL. Human constitution in clinical medicine. London: Paul B Hoeber, 1944

4 Malhotra SL. Peptic ulcer in India and its aetiology. Gut 1964;5:412-6.
5 Todd JE, Whitworth A. Adult dental health in Scotland. London: HMSO, 1972. (Accepted 12 October 1984)

Gastrointestinal Unit, University of Edinburgh, Western General Hospital, Edinburgh EH4 2XU

WILFRED SIRCUS, $M D$, FRCP, consultant physician and reader in medicine

Medical Computing and Statistics Unit, University of Edinburgh Medical School, Edinburgh EH8 9AG

ROBIN J PRESCOTT, MSC, PHD, senior lecturer

Correspondence and requests for reprints to: Dr Wilfred Sircus.

\section{Vascular occlusion and disseminated intravascular coagulation in falciparum malaria}

Disseminated intravascular coagulation is the probable cause of the renal, pulmonary, and cerebral complications seen in falciparum but not in benign tertian or quartan malaria, ${ }^{1}$ but how the abnormality in coagulation is produced is not known. We suspected that the red blood cells containing parasites might be responsible for initiating disseminated intravascular coagulation in falciparum malaria, and so we compared the procoagulant activity in red blood cells from control patients and from patients infected with Plasmodium falciparum and $P$ vivax.

\section{Patients, methods, and results}

Shortening of the one stage plasma recalcification time of normal plasma was taken as an index of red cell procoagulant activity. ${ }^{2}$ The plasma recalcification time of normal pooled plasma (pool of six samples) obtained on each day of the study was taken as $100 \%$ in the calculation of the effect 